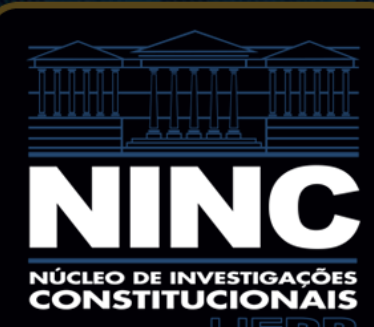




\section{Nasce a Revista de Investigações Constitucionais}

\section{It is born the Journal of Constitutional Research}

É com enorme satisfação que o NINC - Núcleo de Investigações Constitucionais do Programa de Pós-Graduação em Direito da UFPR lança este primeiro número da Revista de Investigações Constitucionais, periódico científico eletrônico e de acesso aberto, cujos artigos são selecionados pelo sistema double blind peer review mediante aprovação de dois pareceristas portadores do título de Doutor e que adota como linha editorial a linha de pesquisa do Núcleo.

O NINC foi fundado em 2011 sob a liderança do Prof. Dr. Titular Clèmerson Merlin Clève no Programa de Pós-Graduação em Direito da Universidade Federal do Paraná, e atualmente conta com a presença do Prof. Dr. Titular Romeu Felipe Bacellar Filho, da Profa Dra Eneida Desiree Salgado, do Prof. Dr. Emerson Gabardo e do Prof. Dr. Daniel Wunder Hachem - todos docentes efetivos do Departamento de Direito Público da UFPR - na direção de suas atividades.

O Núcleo tem como missão a promoção de pesquisas de excelência e seminários de investigação aprofundados na área do Direito Constitucional, notadamente no que diz respeito às teorias da justiça, à democracia e à intervenção, bem como às interfaces do fenômeno constitucional com o Direito Administrativo, o Direito Eleitoral e a Teoria do Estado. Os membros do NINC entendem que a verdadeira atividade de investigação científica é aquela que produz impactos nos meios acadêmico e social

Como citar este editorial | How to cite this editorial: HACHEM, Daniel Wunder. Editorial: Nasce a Revista de Investigações Constitucionais. Revista de Investigações Constitucionais, Curitiba, vol. 1, n. 1, p. 4-6, jan./abr. 2014. DOI: http://dx.doi.org/10.5380/ rinc.v1i1.44818. 
mediante a publicação dos resultados das pesquisas realizadas. Daí a importância de fundar uma revista jurídica que cumpra com os padrões exigidos pelas mais relevantes fontes de informação e bases de dados nacionais e internacionais.

Com vistas a difundir o que há de mais atual nos debates constitucionais de ponta contemporaneamente, a presente revista propõe-se a oferecer ao público leitor artigos científicos de pesquisadores qualificados, priorizando a publicação de trabaIhos de autores exógenos ao Estado do Paraná, redigidos por ao menos um autor com o título de Doutor e conferindo especial atenção às experiências do Direito Comparado, às pesquisas desenvolvidas por autores vinculados a universidades estrangeiras e aos estudos redigidos em inglês e outras línguas além do português.

Nesta edição inaugural, temos a honra de contar com artigos em 3 idiomas (inglês, espanhol e português), de autores vinculados a 6 instituições de ensino superior de 3 países diferentes (Espanha, Argentina e diferentes Estados-membros da República Federativa do Brasil - São Paulo, Rio de Janeiro e Pernambuco). Dos trabalhos publicados, $83 \%$ são de Professores Doutores, 83\% redigidos em língua estrangeira, 50\% de autores estrangeiros e $100 \%$ de autores exógenos ao Estado do Paraná. São eles:

- Revolution trough Constitution: the Brazilian's directive constitution debate

\section{Gilberto Bercovici}

Professor Titular de Direito Econômico da Universidade de São Paulo (São Paulo-SP)

- Recognizing the public right to healthcare: the approach of Brazilian courts

\section{Ricardo Perlingeiro}

Professor Titular da Universidade Federal Fluminense (Rio de Janeiro-RJ)

- Control judicial del estado de sitio y de la intervención federal

\section{Estela B. Sacristán}

Profesora Adjunta de Derecho Administrativo de la Universidad Católica Argentina (Buenos Aires, Argentina)

- Caraterizacion constitucional de la ética pública (Especial referencia al marco constitucional español)

\section{Jaime Rodríguez-Arana Muñoz}

Profesor Catedrático de Derecho Administrativo de la Universidade da Coruña (La Coruña, Espanha)

- Algunas reflexiones sobre la delegación legislativa en Estados Unidos de Norteamérica y en la República Argentina

\section{Raquel Cynthia Alianak}

Profesora Titular de Derecho Administrativo de la Universidad Nacional de Rosario (Rosario, Argentina) 
- Uma ideia de Constituição

\section{Edilson Pereira Nobre Júnior}

Professor Associado da Universidade Federal de Pernambuco (Recife-PE)

Com a expectativa de cumprir o objetivo proposto, com o incremento da divulgação de relevantes trabalhos de investigação jurídica por meio da presente revista científica, desejamos uma excelente leitura.

Curitiba, abril de 2014.

\section{Prof. Dr. Daniel Wunder Hachem}

Coordenador Editorial da Revista de Investigações Constitucionais 